\title{
Career Compromises and Dropout from Voca- tional Education and Training in Germany.
}

Janina Beckmann ${ }^{1}$, Alexandra Wicht ${ }^{2}$, Matthias Siembab $^{1}$

\section{Author notes}

1 Federal Institute for Vocational Education and Training, Bonn, Germany

2 University of Siegen, Department of Education \& Psychology, Germany

Correspondence concerning this article should be addressed to Janina Beckmann, janina.beckmann@bibb.de

\section{Acknowledgements}

The authors thank Martin Wetzel, Marita Jacob and the participants of the 5th International NEPS Conference 2020 for valuable comments on an earlier version of this manuscript. The analyses are based on data from the National Educational Panel Study (NEPS): Starting cohort 4, DOI:

10.5157/NEPS:SC4:10.0.0. From 2008 to 2013, NEPS data were collected as part of the Framework Program for the Promotion of Empirical Educational Research funded by the German Federal Ministry of Education and Research (BMBF). As of 2014, NEPS is carried out by the Leibniz Institute for Educational Trajectories (LIfBi) at the University of Bamberg in cooperation with a nationwide network.

\section{Keywords}

Career compromise, dropout, career expectation, vocational education and training, National Educational Panel Study 


\section{Career Compromises and Dropout from Voca- tional Education and Training in Germany.}

This study investigates the relevance of career compromises (i.e. the discrepancy between expected and attained training position) for dropping out from vocational education and training (VET), focusing on compromises in terms of field of work, social status and gender type. Moreover, it examines whether apprentices' enjoyment of training explains this association. Using longitudinal data on 5,600 apprentices from the German National Educational Panel Study (NEPS, Starting Cohort 4), the results of discrete event history models show that all types of compromises are crucial for VET dropout, but especially compromises regarding field of work and downward discrepancies in gender type. Furthermore, the link between compromises and VET dropout is partly mediated by apprentices' enjoyment of training, which itself is highly correlated with dropping out. These findings draw attention to the role of pre-entry VET policies, such as career counselling, in minimising the incidence of career compromises.

\section{Introduction}

In the German labour market, having obtained an apprenticeship is key to a successful school-to-work transition (Masdonati et al., 2010) which, in turn, leads to relatively stable occupational careers and avoids unemployment (Manzoni et al., 2014; Müller et al., 1998; Solga, 2008). At the same time, however, around 25 percent of apprenticeship contracts in the dual system are terminated prematurely each year, a constant characteristic of the German vocational training system (VET) over the past decades (Uhly, 2015). ${ }^{1}$ This is of particular concern as dropping out of VET can have severe consequences for young people's later lives, such as a high "labour market vulnerability", stigmatization and lower social status (Solga, 2008). 
Moreover, training dropouts come along with costly losses of resources at the level of companies (Wenzelmann and Lemmermann, 2012). In order to take targeted educational policy measures to prevent dropping out from VET, it is therefore of particular interest to identify their precursors.

Previous research has found manifold predictors of apprenticeship dropouts (e.g. Uhly, 2015). The majority of studies highlight the relevance of individual characteristics (e.g. school-leaving certificates, migration background; see e.g. Beicht and Walden, 2013; Bessey and Backes-Gellner, 2015; Rohrbach-Schmidt and Uhly, 2015; Stalder and Schmid, 2016), financial resources (Bessey and Backes-Gellner, 2015; Seidel, 2019) and structural characteristics of occupations and training firms (Christ, 2013; Rohrbach-Schmidt and Uhly, 2015).

Another important strand of research focusses on the role of youths' career choices in predicting VET dropout. While some studies attribute dropouts to poorly informed career decisions (Beinke, 2010 ; Uhly, 2015), other studies take into account that career choices are made against the backdrop of various constraints that often require "career compromises" (Ahrens et al., 2021; Gottfredson, 2002), which is reflected in the higher dropout rates of youth who did not obtain an apprenticeship in their desired occupation (Beicht and Walden, 2013). Moreover, Creed and Saporta (2003) found that career compromises are associated with job quitting and job changes.

Aside from the empirical findings on the role of career compromises, there is a lack of research on the relevance of different types of career compromises for dropping out from VET (for an exception see Taris et al., 2006). Moreover, the reasons why career compromise leads to dropout have not yet been investigated. Following Hardie's (2014) findings that career compromises are associated with job satisfaction and also with depressive symptoms, the reason for higher dropout rates among youth who make compromises when entering VET could be their lower job satisfaction.

The aim of this article is twofold: (1) we examine the relevance of different types of compromises for VET dropouts to shed light on which occupational characteristics constitute compromises that are critical for VET dropouts. We distinguish compromises in terms of field of work, gender 
type and social status. (2) We investigate the role of apprentices' enjoyment of training in explaining the association between different types of compromises and dropout from VET. To this end, we use longitudinal data on 5,600 apprentices from the German National Educational Panel Study (NEPS, Starting Cohort 4), which provide detailed information on youths' career expectations, the VET position they attained after general schooling and assessments of their current training situation in addition to dropout behaviour.

\section{Theoretical Framework: Youths' Dropout from VET in Light of Career Compromises}

\subsection{Linking career compromises, dissatisfaction and dropout from VET}

There is no comprehensive theory that specifically links youth dropout behaviour to career compromises, that is, youths' failure to attain their career expectations. However, there are several pertinent theoretical perspectives and empirical evidence that can guide the current work on the relationship between dropout from VET and career compromise explained by youths' job satisfaction.

Following circumscription and compromise theory (Gottfredson, 1981), career choice serves to establish one's vocational self-concept, that is, one's vocational identity and social role in society (Super, 1957). Youths' career expectations are seen to be the result of establishing one's vocational selfconcept while adapting to perceived real-life opportunities and constraints. Thus, not attaining one's career expectations is a violation of one's vocational identity and occupations that are highly incompatible with one's self are strongly disliked (Gottfredson, 1981). Career theories agree that the implementation of one's self-concept is crucial for job satisfaction (Super, 1957). 
Socio-psychological theories such as self-discrepancy theory (Higgins, 1987) and multiple discrepancies theory (Michalos, 1985) generally consider the realization of one's goals and preferences as the primary source of self-satisfaction and feelings of success. Both theories identify the perceived discrepancy between preferences and attainment as a central predictor of one's psychological well-being and satisfaction. Not attaining goals and preferences invokes negative emotions such as disappointment, dissatisfaction, self-criticism or frustration. Person-environment fit theory (Edwards and Shipp, 2007; Holland, 1997) in particular attributes job dissatisfaction and distress to a mismatch between a person's needs (including their desires and goals) and the characteristics of their vocational environment (e.g. job requirements and tasks).

In this regard, previous studies found that a high congruence between the person and their vocational environment is associated with higher job satisfaction and organizational commitment (for an overview see KristofBrown et al., 2005). Also, not attaining career aspirations is associated with lower psychological well-being and higher levels of distress (Carr, 1997; Creed and Blume, 2012; Hardie, 2014; Tsaousides and Jome, 2008; for contradictory evidence see Reynolds and Baird, 2010). Empirical studies investigating career outcomes found that unmet aspirations are associated with lower levels of career satisfaction, work adjustment and work motivation (Ashforth and Saks, 2000; Creed and Gagliardi, 2015; Irving and Montes, 2009; Tsaousides and Jome, 2008; Turnley and Feldman, 2000). Career compromise was further related to increased sick absence and risk of unemployment (Carr, 1997; Gjerustad, 2016; Gjerustad and Von Soest, 2011).

The theoretical approaches and empirical findings presented above converge in the prediction that a discrepancy between career expectations and the VET position attained leads to dissatisfaction. Understanding dropout from VET as a means to dissolve discrepancies and associated negative feelings, apprentices who experience career compromise are likely to have a higher risk to leave their apprenticeship (to improve upon their situation). This assumption finds support by empirical evidence on the returns to job mobility, which shows that a job change is often accompanied by an 
improvement in terms of job satisfaction, organizational commitment, income and status (e.g. Gesthuizen and Dagevos, 2008; Kalleberg and Mastekaasa, 2001; for apprenticeships see Schmid and Stalder, 2012). Also, studies suggest that career compromises are associated with a higher probability of searching for a new job and higher rates of turnover (Creed and Saporta, 2003; Pearson, 1995; Taris et al., 2006). Concerning apprentices, analyses for Germany found that not attaining one's desired training occupation was associated with higher dropout from VET (Beicht and Walden, 2013).

\subsection{Types of career compromise}

What constitutes a career compromise and what types of career compromises play a role in youth dropout from VET? These are important questions that have not been taken into account in the previous considerations. Drawing on Gottfredson's $(1981,2002)$ distinction of individuals' vocational self-concept into a social self and a psychological self, types of career compromises related to different occupational characteristics can be theoretically linked with dropout behaviour. The individual's social self refers to the expected career gender type and social status and the psychological self pertains to the expected field of work.

\section{Compromises towards psychological self: field of work}

The field of work component of the vocational self-concept relates to a conglomerate of vocational interests, competencies and personal values (Gottfredson, 1981). This description resembles the sociological conceptualization of occupations as unique bundles of skills, tasks, institutional regulations and cultures (for a theoretical overview see Haupt and Ebner, 2020). Holland's theory of vocational personalities and work environments (e.g. Holland, 1997) points to the importance of congruence between individuals' career interests and their work environment for successful vocational learning. Discrepancies regarding field of work can also be understood in terms of a cultural misfit. The micro class approach emphasises the horizontal stratification of labour markets along occupations or 
occupational groups. In this view, employees within an occupation share not only similar occupational tasks, skill demands and working conditions, but also distinct value orientations and lifestyles (Grusky and Weeden, 2006; Jonsson et al., 2009). Empirical studies support the existence of such occupational cultures or identities (Blyton and Bacon, 1997; Collinson, 2006; McAndrew et al., 2019). Hence, if students' expectations for a specific occupation are unmet, they might experience a misfit not only in terms of their vocational interests, but also regarding their vocational identity and culture. Field of work compromises might be particularly detrimental when discrepancies are strong. For example, an individual may expect to work as a nurse but end up working as a medical clerk. Since these two occupations are quite similar in terms of required tasks, skills, working conditions and potentially lifestyles, such minor compromises are likely to be less harmful than compromises transgressing strongly demarcated boundaries of fields of work.

\section{Compromises towards social self: gender type and social status}

Regarding the gender type and social status components of vocational selfconcept, theoretical accounts point to the importance of compromises that exhibit either a directional or a nondirectional relationship to dropout behaviour. A directional relationship between career compromise and dropout exists when the risk of dropping out increases (decreases) if the VET position attained is less (more) gender-typical and has a lower (higher) social status than the expected career. In turn, a nondirectional relationship between career compromise and dropout occurs when the risk of dropping out increases if the VET position attained generally does not match the youth's expected social status and gender type (irrespective of the direction of the discrepancy).

\section{Directional relationships}

With regard to discrepancies in social status, theories of (bounded) rational educational decisions (e.g. Boudon, 1974; Breen and Goldthorpe, 1997) suggest that youths' career expectations are the result of cost-benefit considerations and that they evaluate their career attainment primarily based 
on expected benefits (income, social status): the higher the social status of the VET position attained compared to their expectations, the higher the value young people attach to it. Moreover, level of aspiration theory (e.g. Starbuck, 1963) considers the level of aspirations as a reference point for feelings of success and failure. The lower the attainment with respect to this reference point, the more negative emotions individuals feel - and vice versa (Heath et al., 1999). Empirical support is provided by Carr (1997), who finds that the risk of developing mental health problems increases with the distance between the occupational status of aspired and actual position. Gjerustad (2016) further found that attaining a lower social status than expected increased the risk of unemployment. With this in mind, if the social status of the attained VET position falls below the aspired one, negative emotions arise that increase the risk of dropping out of VET. Conversely, attaining a VET position that confers a higher social status than aspired should be associated with more positive emotions and a lower dropout risk.

Concerning compromises regarding gender type, the concept of tokenism by Kanter (1977) frames the experiences of individuals who are minorities in their workplace or occupation (Busch, 2013; Kanter, 1977; Taylor, 2010, 2016). A key finding is that the more skewed the gender ratio in an occupation, the more attention the minority (token) group receives from the dominant group. As a result, minorities often operate under greater pressure to perform (Kanter, 1977). This is often accompanied by a less supportive work climate (Busch, 2013; Taylor, 2010), higher physical stress (Taylor, 2016) and even a higher probability of early contract cancellation (Rohrbach-Schmidt and Uhly, 2015). Such negative repercussions are less pronounced for individuals in more balanced work settings or for individuals who belong to an occupational majority (Kanter, 1977). Thus, the more gender-atypical the attained VET position relative to their expectations, the lower youths' satisfaction with their VET position, which should lead to a higher dropout risk. Conversely, youths should be more likely to be satisfied and at lower risk of dropping out if they attain a VET position that is equally or more gender-typical than their previous career expectations. 


\section{Nondirectional relationships}

Following Bourdieu's (1979) notion of habitus, any career compromise in gender type and social status - be it a downward or upward discrepancyshould lead to dissatisfaction and thus higher risk of dropout. Habitus comprises individuals' patterns of perception, interpretation and action that are shaped by social categories such as social class and gender (see also Colley et al., 2003). Individuals express their class membership through certain aesthetics, attitudes, speech and social networks and in this way constantly reproduce their social position. Previous studies have shown that when social class habitus and context do not correspond, feelings of ambivalence, insecurity and unease emerge (Sennett and Cobb, 1972), e.g. regarding the situation of working-class students at university (Reay, 2005). Therefore, the presence of an occupational habitus can be assumed.

Moreover, studies have coined the term gender habitus to refer to the social construction of gender and the different gender-specific behaviours and expectations that are perceived as typical feminine or masculine (Behnke and Meuser, 2001; Schwiter et al., 2011). Gender habitus is thus a critical filter by which occupations are perceived and career expectations are established. It is therefore also part of the occupational habitus of the individual.

Importantly, gender habitus is a continuum of different more or less rigid expressions of femininity and masculinity (Behnke and Meuser, 2001), that is, some individuals adhere to traditional gender norms, constructing men and women as highly distinct social categories, while others express a less rigid construction of gender. Consequently, youth who enter occupations that are not congruent with their expected gender habitus will experience "habitual insecurity". The salience of gender and the gender continuum is also visible in the structure of the German labour market: although the majority of occupations can be described as either typical male or female, there is strong variability in the extent to which occupations are skewed towards gender. Occupations, thus, may not only be perceived as too gender-atypical (as argued above), but may also be conceived as too gendertypical in relation to one's gender habitus. 


\section{The present study}

Previous theories and research emphasise the relevance of career compromise to VET dropout. However, little is known about the occupational characteristics that constitute career compromises that are crucial for dropping out of VET and its reasons. Using longitudinal data on 5,600 apprentices from the National Education Panel Study (NEPS, Start Cohort 4), the relevance of different types of career compromises is examined: compromises related to field of work, gender type and social status. The role of apprentices' enjoyment of training is explored in explaining the association between these different types of compromises and dropout. The following hypotheses are investigated:

H1 (field of work): A discrepancy between the VET position attained and the expected VET position in terms of field of work leads to a higher probability of dropping out. This association is more pronounced for strong discrepancies than for moderate discrepancies.

H2a (downward social discrepancy): The probability of dropping out increases if the social status of the VET position attained is lower than expected. Exceeding the expected social status lowers the dropout probability.

H2b (downward and upward social discrepancy): Attaining a VET position incongruent with one's expected social status increases the dropout probability (irrespective of whether the attained VET position exceeds or falls short of the expected social status).

H3a (downward gender-type): The probability of dropping out increases if the gender type of the VET position attained is lower than expected. A more gender-typical VET position than expected lowers the dropout probability.

H3b (downward and upward gender-type): Attaining a VET position incongruent with one's expected gender type increases the dropout probability (irrespective of whether the attained VET position is more gendertypical or more gender-atypical than expected).

H4 (mediation): The association between the different types of career compromise and dropout from VET is mediated by enjoyment of training. 


\section{Data and Methods}

\subsection{Data}

This study uses the German survey data from the NEPS, Starting Cohort 4 (SC4), version 10.0.0, doi:10.5157/NEPS:SC4:10.0.0 (Blossfeld et al., 2011). The NEPS-SC4 survey includes a representative sample of students attending ninth grade at regular schools in Germany and covers students' transition from the general school system to the VET system and their further course therein. The first survey was carried out in the classroom via paper-and-pencil interviewing (PAPI) in autumn 2010 (Wave 1), followed by a second survey in spring 2011 (Wave 2). From tenth grade onwards, subsequent surveys took place annually in the classroom via PAPI (Waves 3-8). Persons who had left the general education system were interviewed biannually (Waves 3-6) and later annually (Wave 7 onwards) using computer-assisted telephone interviewing (CATI). Data from Wave 1 to Wave 10 are used.

The analytical sample includes students who graduated from general secondary school after lower or upper secondary education (usually with a lower [Hauptschulabschluss] or intermediate [Realschulabschluss] secondary school certificate after grade 9 or 10 or with the German university entrance qualification [Fachhochschulreife/Abitur] after grade 12 or 13). 7,388 individuals entered VET after graduating from general schooling. Individuals with missing values on career expectations or VET position attained were excluded since these are the primary variables of interest. Furthermore, apprentices who entered VET abroad or on a part-time basis were excluded. The final analytical sample included 5,600 apprentices. 


\section{Measures}

\subsection{Focal variables}

Dropout from VET. The dependent variable captures apprentices' dropout from their first full-qualifying VET position (0 no dropout, 1 dropout), which is based on apprentices' self-reported, retrospective information on a monthly basis. Dropout includes complete leave from the VET system and turnover to another VET position (but a distinction between these types of dropout is not made). VET episodes lasting longer than 40 months (which approximates the average maximum duration of VET in Germany) were truncated and treated as right-censored, to avoid noise in the analyses due to a small number of artificial dropouts at late observation points.

Career compromises. The different types of career compromise were constructed based on students' career expectations measured in grade 9 or - in case of missing data-in grade 10 ("Think about everything you know right now. Which profession do you think you will actually have later?") and their first full qualifying VET position. To map the field of work of both, career expectations and VET position attained, this study draws on the German Classification of Occupations (KldB 2010) which contains four distinct levels capturing the similarity of occupations regarding their Berufsfachlichkeit (i.e. their similarity with respect to vocational tasks, competences and knowledge, for details see Paulus and Matthes, 2013). Three levels of compromise based on the occupational level at which discrepancies between expected and attained apprenticeship occur are considered: i) no compromise (there is no discrepancy at the most detailed 4-digit level, the reference category), ii) moderate compromise (discrepancy at the 4-digit or 3-digit level) and iii) strong compromise (discrepancy at the 2-digit or 1-digit level).

Social status compromise was measured based on the International Socio-Economic Index (ISEI) which takes values between 16 and 90 (Ganzeboom et al., 1992). No compromise (reference category) means that apprentices realised the social status they expected to attain while downward 
compromise relates to a lower attained social status and upward compromise refers to a situation when apprentices attained a higher social status than expected. Discrepancies of more than 10 scale points are defined as career compromises, to consider only stronger compromises.

Gender type compromise was constructed based on the share of samesex employees in an occupation (employment statistics of the Federal Employment Agency, 2014). Similarly, the reference category no compromise comprises apprentices who attained their expected gender type, while the downward compromise refers to deviations toward gender-atypical occupations and the upward compromise to deviations toward higher gender-typicality. Discrepancies greater than 10 percentage-points were considered as compromises, to encompass only stronger compromises.

Enjoyment of training. Apprentices' enjoyment of the training was measured by their agreement with the statement "My training is fun" on a 5 -points scale. Because the information is collected annually, it was operationalised as a time-varying variable.

\subsection{Control variables}

Gender. Apprentices' gender was coded such that men represented the reference group.

Migration background. The variable was included as three categories: no immigration background, 1 st generation immigrants and 2nd generation immigrants. The variable is based on information on students' country of birth as well as the country of birth of students' parents and grandparents (Olczyk et al., 2014). $1^{\text {st }}$ generation immigrants are those individuals who were born in Germany and $2^{\text {nd }}$ generation immigrants are those individuals who were born in Germany but whose parents were both born outside of Germany.

Educational qualification. The variable refers to the highest school leaving qualification attained before entering VET, distinguishing between low (Hauptschulabschluss, the reference category), medium (Mittlere Reife) and high (Fachhochschulreife/Abitur) educational qualifications. 
Type of Training. The variable refers to the apprentices' statements about their training type. In Germany, there are two types of VET, which is either firm-based or school-based. The variable was coded such that firmbased training represented the reference group.

Occupational segments. The variable represents an aggregation of occupations into 14 occupational groups according to their occupational similarity and distinctiveness based on the 2-digit-level of the KldB 2010 (Matthes et al., 2015). Due to low number of cases in some segments, the occupational segments were further coded into 12 categories.

Duration of training. The variable refers to the time apprentices already have spent in training by four categories, $1^{\text {st }}$ half-year (reference category), $2^{\text {nd }}$ half-year, $2^{\text {nd }}$ year and after $2^{\text {nd }}$ year.

Table 1 shows the descriptive statistics of the analytic sample.

Table 1. Descriptive statistics.

\begin{tabular}{|c|c|c|c|c|c|}
\hline Variables & Mean/percent & sd & $\min$ & $\max$ & $\mathbf{N}($ valid $)$ \\
\hline \multicolumn{6}{|l|}{ Dependent variable } \\
\hline Dropout from VET & 13.91 & & 0 & 1 & 5600 \\
\hline \multicolumn{6}{|l|}{ Career compromise } \\
\hline Occupational specialty & & & 0 & 1 & 5600 \\
\hline No compromise (ref.) & 29.63 & & & & \\
\hline Weak compromise & 13.18 & & & & \\
\hline Strong compromise & 57.20 & & & & \\
\hline Social status & & & 0 & 1 & 5600 \\
\hline No compromise (ref.) & 56.20 & & & & \\
\hline Downward compromise & 18.30 & & & & \\
\hline Upward compromise & 25.50 & & & & \\
\hline Gender-type & & & 0 & 1 & 5600 \\
\hline No compromise (ref.) & 60.63 & & & & \\
\hline Downward compromise & 28.84 & & & & \\
\hline Upward compromise & 10.54 & & & & \\
\hline \multicolumn{6}{|l|}{ Mediator } \\
\hline Enjoyment of training & 4.48 & 0.74 & 1 & 5 & 5600 \\
\hline \multicolumn{6}{|l|}{ Controls } \\
\hline Gender: female & 48.46 & & 0 & 1 & 5600 \\
\hline
\end{tabular}




\begin{tabular}{lccc} 
Migration background & & 0 & 1 \\
German (ref.) & 76.73 & & \\
$1^{\text {st }}$ generation migrant & 5.71 & & \\
$2^{\text {nd }}$ generation migrant & 17.56 & 1 & 5102 \\
School type & & & \\
Low (ref.) & 25.15 & & \\
Medium & 52.20 & & \\
High & 22.66 & 0 & 5600 \\
Occupational segment & & & \\
Production (ref.) & 34.02 & & \\
Personal service & 33.07 & & \\
Commercial service & 25.02 & & \\
IT and scientific service & 3.96 & & \\
Other economic service & 3.93 & & \\
Dual training (vs. school-based) & 77.29 & & \\
\hline
\end{tabular}

\subsection{Statistical Analyses}

In order to investigate associations between the different types of compromises when entering VET and dropout from training, discrete-time event history models are used (Allison, 1982) in Mplus 8.7 (Muthén and Muthén, 2012-2019). The model corresponds to a binary logistic regression model. The dependent variable is the transition probability from state 0 (being in VET) to state 1 (dropping out from VET). The transition probability is defined as the log-odds for the conditional probability of dropping out at time $t_{i}$. Since the transition probability depends on the process time (i.e., the duration in training that has already passed), a piecewise-constant modelling strategy is used, where the transition probability is assumed to be constant only within particular time intervals (Blossfeld and Rohwer, 2002). To map this, controls for process time intervals are included (see section on 'Control variables').

Path models are used to examine if the relationship between compromises and dropout can partly be traced back to differences in apprentices' enjoyment of training. Those models enable us to separate the direct associations between compromises and dropout and the indirect associations 
between compromises and dropout through apprentices' enjoyment of training. The indirect associations were calculated by the product of coefficients method; the standard errors for all relationships, total, direct and indirect, were obtained via bias-corrected bootstrap (10,000 replications), as this procedure does not require assumptions about the sampling distribution of estimated effects (MacKinnon, 2008).

A Weighted Least Square Mean and Variance Adjusted (WLSMV) estimator and Full Information Maximum Likelihood estimation method (FIML) were used to handle missing data. The level of analysis corresponds to person-months, not persons. To address the resulting problem of nonindependence of person-month observations, cluster-robust standard errors were obtained by means of a Huber-White sandwich estimator(Williams, 2000). In all models, gender, migration background, school type, duration of training, occupational segment of VET position and type of training were included as covariates, to rule out the possibility that differences between compromises and dropout are in part due to differences in those variables (Rohrbach-Schmidt and Uhly, 2015).

\section{Results}

\subsection{Are career compromises associated with dropout?}

Figure 1 shows the results of the path models on the relationships between dropping out of VET and the different types of compromises youths had to make when entering VET - compromises related to the field of work, social status and gender type of occupations. The full regression results including the associations between dropout and control variables can be found in Table A1 of the appendix. 
Figure 1. Relationships between the different types of compromises, enjoyment of training and dropping out of VET.

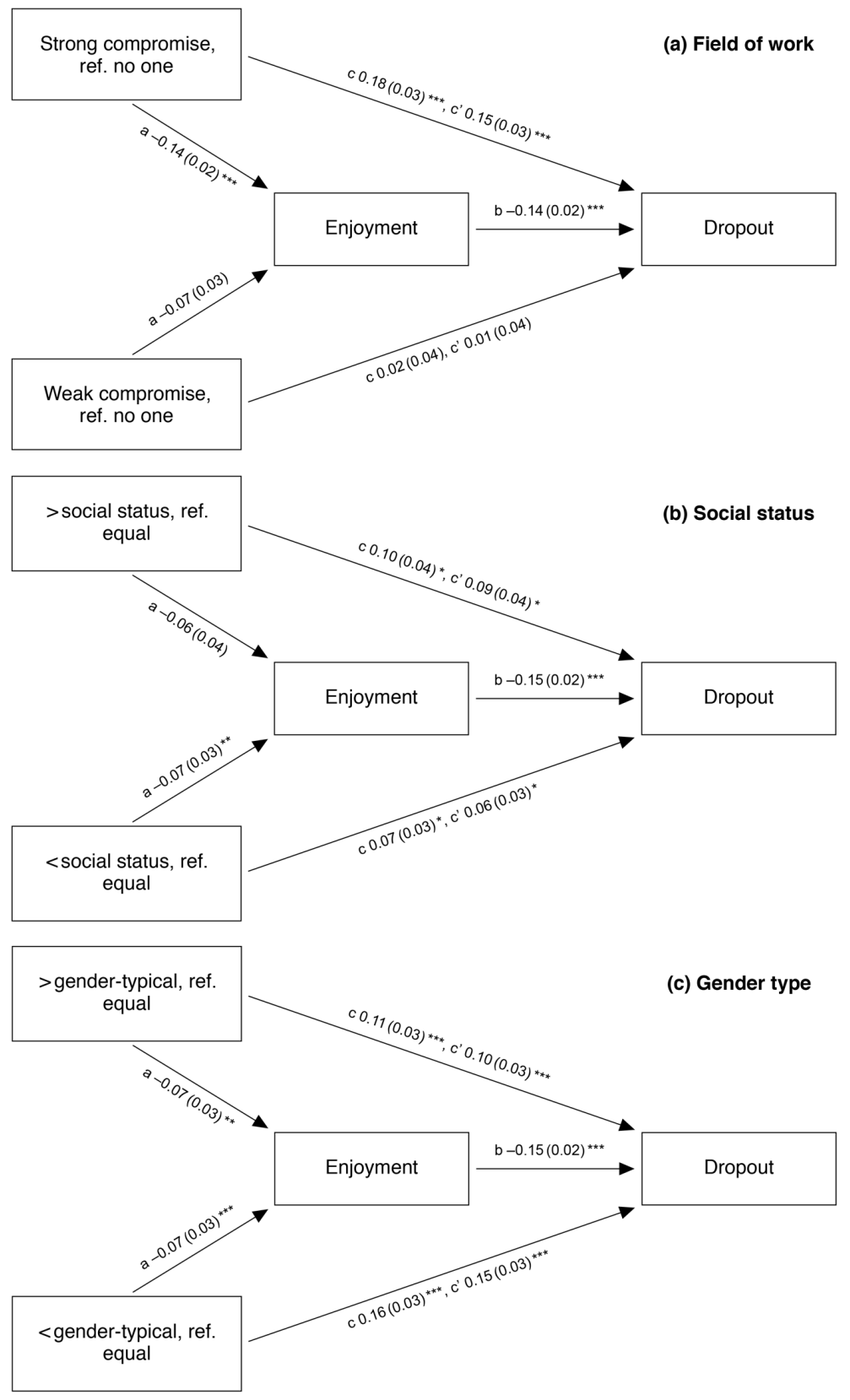

Notes. The paths a were estimated by a linear regression models and the paths b, c and c' by a logistic regression models (logits were reported). Standard error in parentheses. Control variables are gender, migration background, educational qualification, duration of training, occupational segment of VET position and type of training. $\mathrm{N}$ (person-months $)=118,820, \mathrm{~N}($ apprentices $)=5,600$. Path coefficients are statistically significant at $* \mathrm{p}<.05, * * \mathrm{p}<.01, * * * \mathrm{p}<.001$. 
Paths $\mathrm{c}$ of Figure 1 show the total associations between the different types of compromises and dropout from VET. The most important association can be observed between strong compromises in field of work and dropout; weak compromises regarding field of work were not associated with dropout (see Figure 1, panel a). Apprentices who had to make severe compromises regarding their field of work upon entering VET were $19 \%$ more likely to drop out from VET $\left[\left(\mathrm{e}^{0.17}-1\right) * 100\right]$ compared to those who did not have to make any compromise, supporting hypothesis 1 . It is important to note that effect sizes for compromises related to field of work can only approximately be compared to those related to social status and gender type, as the thresholds used to operationalise compromises are different by construction based on the data used. Still, the present operationalization of social status and gender type compromises may map upward and downward compromises that are roughly comparable to strong compromises related to the field of work (see section on 'Focal variables').

Consistent with hypothesis $2 \mathrm{~b}$ and hypothesis $3 \mathrm{~b}$, the association between any kind of career compromise concerning social status and gender type were also found to be statistically significantly predictive of dropout, albeit the results for compromises in social status are statistically less well supported. The strongest correlation was found between downward gender type compromises and dropout probability. With a $17 \%$ higher dropout probability, apprentices who entered VET that is less gender-typical than their expected occupation are especially prone to dropout. Thus, with respect to the direction of compromises in social status and gender type, the directional hypotheses $2 \mathrm{a}$ and $3 \mathrm{a}$ were not supported, but the non-directional hypotheses $2 \mathrm{~b}$ and $3 \mathrm{~b}$ were.

\subsection{Does enjoyment of training contribute to explaining the association between career compromises and VET dropout?}

Looking at paths $b$ in Figure 1, the models suggest that regardless of the experience of compromises when entering VET, apprentices' enjoyment of training is a strong predictor of dropout. When enjoyment of training, 
measured on a 5-points scale, increases by one scale value, the probability of dropout decreases by $15 \%$. Enjoyment of training is also related to the different types of compromises, although associations are small. All types of compromises are associated with lower enjoyment of training, except for weak compromises regarding field of work. The strongest association was observed between strong compromises related to field of work compared to no compromise and enjoyment of training, with apprentices showing 0.14 lower enjoyment of training.

Table 2. Total, direct and indirect associations between compromises and VET dropout.

\begin{tabular}{|c|c|c|c|c|c|c|c|c|c|}
\hline & \multicolumn{3}{|c|}{ Total association } & \multicolumn{3}{|c|}{ Direct association } & \multicolumn{3}{|c|}{ Indirect association } \\
\hline & Odds & Logits & $S E$ & Odds & Logits & $S E$ & Odds & Logits & $S E$ \\
\hline \multicolumn{10}{|l|}{ Occupational specialty } \\
\hline \multicolumn{10}{|l|}{ No compromise (ref.) } \\
\hline Weak compromise & n.s. & 0.019 & $(0.042)$ & n.s. & 0.009 & $(0.042)$ & n.s. & 0.010 & $(0.005)$ \\
\hline Strong compromise & 1.190 & 0.174 & $(0.029)$ & 1.166 & 0.154 & $(0.029)$ & 1.021 & 0.021 & $(0.004)$ \\
\hline \multicolumn{10}{|l|}{ Gender-type } \\
\hline \multicolumn{10}{|l|}{ No compromise (ref.) } \\
\hline Downward compromise & 1.117 & 0.111 & $(0.030)$ & 1.105 & 0.100 & $(0.030)$ & 1.011 & 0.011 & $(0.004)$ \\
\hline Upward compromise & 1.169 & 0.156 & $(0.034)$ & 1.156 & 0.145 & $(0.034)$ & 1.010 & 0.010 & $(0.005)$ \\
\hline \multicolumn{10}{|l|}{ Social status } \\
\hline \multicolumn{10}{|l|}{ No compromise (ref.) } \\
\hline Downward compromise & 1.095 & 0.095 & $(0.041)$ & 1.090 & 0.086 & $(0.041)$ & n.s. & 0.009 & $(0.006)$ \\
\hline Upward compromise & 1.076 & 0.073 & $(0.031)$ & 1.065 & 0.063 & $(0.031)$ & 1.011 & 0.011 & $(0.004)$ \\
\hline
\end{tabular}

Table 2 shows the total, direct and indirect associations between the different types of compromises and dropout from VET. As expected, given the small correlations between the different types of compromises and enjoyment of training, the indirect correlations between compromises and dropout from VET via enjoyment of training are small as well, albeit not negligible, supporting hypothesis 4 . Again, strong compromises related to field of work were most strongly associated with dropout from VET. Strong compromises with respect to field of work are associated with a $2.1 \%$ increase in dropout probability, which can be attributed to the fact that 
apprentices enjoy their training less when making such compromises. Thus, differences in apprentices' enjoyment of training mediate about $11 \%$ of the differences in dropout behaviour between apprentices who had to make strong compromises in field of work and those who were able to realise their expectations. However, there remain strong direct, i.e., unexplained associations between compromises and dropout.

\section{Discussion}

\subsection{Summary}

This article aimed to shed light on the relevance of career compromises for dropping out of VET, focusing on different types of compromises that some apprentices have to accept when entering VET: compromises related to field of work, social status and gender type. Moreover, it investigated the role of apprentices' enjoyment of training in explaining the relationship between such compromises and dropout from VET.

Using representative and comprehensive longitudinal data on apprentices' first full qualifying training position and their career expectations before entering VET, substantial associations between compromises and dropout behaviour were found. In line with previous theorising and research (i.e. Creed and Blume, 2012; Hardie, 2014), all types of compromises were crucial for dropout behaviour. Of particular concern, however, were strong compromises regarding field of work - including compromises in vocational tasks, skills and vocational cultures - as suggested by Holland's (1997) Theory of Vocational Personalities and Work Environment as well as the Sociological Microclass Approach (e.g. Jonsson et al., 2009). In line with Kanter's (1977) tokenism approach, downward compromise in gender type also turned out to be a strong predictor of VET dropout. It is nonetheless noteworthy that, although some of the correlations are small, both upward and downward compromises in gender type and social status were related to higher dropout behaviour, supporting the existence of an 
occupational habitus tied to social status and gender (Bourdieu, 1979; Colley et al., 2003).

The link between compromises in entering VET and dropping out can in part be traced back to apprentices' enjoyment of training, which itself is highly correlated with dropping out. This finding applies to all types of compromises and is particularly pronounced for strong field of work compromises. Hence, any discrepancy between expected and realised training position leads to lower satisfaction and thus lower motivation to complete training, supporting the idea of occupational micro classes with unique occupational task profiles, cultures and identities. However, indirect associations between the different types of compromises and dropout behaviour through enjoyment of training were small and amount to $11 \%$ of total associations or less, leaving room for further investigation of the mediating role of individual and training characteristics in explaining the relationship between compromise and dropout.

\subsection{Limitation and future research}

Our present study certainly has limitations. First, one has to consider our measurement of VET dropouts. It must be taken into account that our analyses do not distinguish which educational path the young people chose after dropping out. It may well make a difference whether young people drop out of the education system altogether or take an educational path that may be more in line with their previous expectations (Beicht and Walden, 2013; Bessey and Backes-Gellner, 2015).

Second, even though a moderating effect of enjoyment of training was established, potential for future research is evident. For example, there may be other variables playing a mediating role in explaining the association between occupational compromises and VET dropout, such as the inability to cope with the training requirements or expectations from significant others. Furthermore, multi-group comparisons could shed light on whether the reported relationships vary across individual, social or contextual 
characteristics, such as gender, social status, resources, type of training or region-specific training or labour market demand.

Finally, there are limitations to the present approach to operationalising career compromise. Using variables that are closer in time to the school-towork transition (e.g. actual VET applications instead of career expectations) might yield stronger effects. In addition, it should be noted that the social status and gender type of an occupation might be correlated to some extent (Siembab and Wicht, 2020); hence, the reported effects of social status and gender type compromise may not be completely separate. Due to the small number of cases in some categories of a combined variable of compromises related to gender type and social status, robust sensitivity analyses could not be performed.

\subsection{Conclusion}

This study builds on and extends an important strand of literature on the consequences of career compromises in school-to-work transitions. Importantly, this study extends previous literature by looking at different types of compromise, thereby yielding a more nuanced picture of the consequences of unmet career expectations in relation to occupational characteristics. Unfulfilled occupational expectations in terms of field of work, social status and gender type are strong predictors of dropping out of VET, a finding which illustrates that career compromise must be understood as a multifaceted phenomenon which cannot be reduced to the binary distinction between "unmet" and "met" expectations. Since compromises in terms of field of work are most detrimental, these findings lend support to the emerging micro-class approach that views occupations as an important and unique source of segmentation of the labour market (Grusky and Weeden, 2006; Jonsson et al., 2009). The finding that both upward and downward gender-type compromises are related to dropout further strengthens the conception of gender habitus as a continuum which can involve more or less rigid expressions of gender (Behnke and Meuser, 2001). 
Furthermore, this study connects two strands of literature which have either looked at satisfaction (e.g. Hardie, 2014) or job quitting (e.g. Creed and Saporta, 2003) separately. The present results show that the association between compromise and dropout is partly due to lower satisfaction with the training and, as a result, probably lower motivation to complete the training. Thus, this study suggests that youth who face structural barriers to pursuing their expectations nonetheless exhibit high levels of agency when their expectations go unfulfilled and may seek a training position that is more suitable for them.

On a more general level, this study reveals a mismatch between supply and demand on the training market, which can lead to strong tensions not only at the level of apprentices, but also of the training market. The findings relate to the phenomenon that young people's expectations have become more concentrated at a small number of occupations, which might not always be realistic and attainable (Mann et al., 2018). Hence, this study highlights the need to establish effective counselling strategies that help young people not only in realising their expectations, but also guide them in exploring and identifying alternative occupational niches that best suit their individual interests, abilities and conceptions of themselves in terms of their occupational identity, social status and gender (Rochat, 2015).

\section{Endnotes}

1 More precisely, around half of these dissolutions can be considered as rather unproblematic revisions of educational decisions, with young people changing occupations and remaining within the VET system, while the other half involve leaving the VET system (Bessey and Backes-Gellner 2015; Uhly 2015). Nevertheless, in this article, the term „dropouts“ refers to both groups. 


\section{References}

Ahrens L, Kleinert C, Fischer M and Schels B (2021) Nicht alle Wünsche werden wahr: Welche Kompromisse Jugendliche beim Ausbildungsberuf eingehen. IAB Forum.

Allison PD (1982) Discrete-Time Methods for the Analysis of Event Histories. Sociological Methodology 13: 61-98.

Ashforth BE and Saks AM (2000) Personal Control in Organizations: A Longitudinal Investigation with Newcomers. Human Relation 53(3): 311-339.

Behnke C and Meuser M (2001) Gender and habitus. Fundamental securities and crisis tendencies among men. In: Kotthoff $\mathrm{H}$ and Baron B (eds) Gender in Interaction. Perspectives on femininity and masculinity in ethnography and discourse. Amsterdam: Benjamins, 153-174

Beicht U and Walden G (2013) Duale Berufsausbildung ohne Abschluss - Ursachen und weiterer bildungsbiografischer Verlauf Analyse auf Basis der BIBB-Übergangsstudie 2011. BIBB-Report 21/13. 1-15.

Beinke L (2010 ) Befragung zum Übergangsmanagement und zur Abbrecherproblematik - Einleitung und Begründung der Abbrecherstudie. Wirtschaft \& Erziehung 62(5): 142147.

Bessey D and Backes-Gellner U (2015) Staying Within or Leaving the Apprenticeship System? Revisions of Educational Choices in Apprenticeship Training. Jahrbücher für Nationalökonomie und Statistik 235(6): 539-552.

Blossfeld H-P and Rohwer G (2002) Techniques of Event History Modeling: New Approaches to Casual Analysis. Mahwah: Lawrence Erlbaum Associates.

Blossfeld H-P, Roßbach H-G and von Maurice J (2011) Education as a Lifelong Process - The German National Educational Panel Study (NEPS). Zeitschrift für Erziehungswissenschaft (Sonderheft 14).

Blyton P and Bacon N (1997) Re-Casting the Occupational Culture in Steel: Some Implications of Changing from Crews to Teams in the UK Steel Industry. The Sociological Review 45(1): 79-101.

Boudon R (1974) Education, Opportunity, and Social Inequality. Chancing Perspective Prospects in Western Societies. New York: Wiley \& Sons.

Bourdieu P (1979) La distinction. Critique sociale du jugement. Paris: Minuit.

Breen R and Goldthorpe JH (1997) Explaining educational differentials: Towards a formal rational action theory. Rationality and Society 9(3): 275-305.

Busch A (2013) Die berufliche Geschlechtersegregation in Deutschland. Wiesbaden: Springer VS.

Carr D (1997) The fulfillment of career dreams at midlife: does it matter for women's mental health? Journal of Health and Social Behavior 38(4): 331-344.

Christ A (2013) Betriebliche Determinanten vorzeitig gelöster Ausbildungsverträge. Berufsbildung in Wissenschaft und Praxis (BWP) 42(3): 4-5.

Colley H, James D, Diment K and Tedder M (2003) Learning as becoming in vocational education and training: class, gender and the role of vocational habitus. Journal of Vocational Education \& Training 55(4): 471-498. 
Collinson JA (2006) Just 'non-academics'?: Research administrators and contested occupational identity. . Work, Employment and Society 20(2): 267-288.

Creed PA and Blume K (2012) Compromise, Well-Being, and Action Behaviors in Young Adults in Career Transition. Journal of Career Assessment 21(1): 3-19.

Creed PA and Gagliardi R-E (2015) Career Compromise, Career Distress, and Perceptions of Employability. Journal of Career Assessment 23(1): 20-34.

Creed WED and Saporta I (2003) Unmet Expectations: The Effect of Status Inconsistency on Quitting and Internal Job Changing. Research in Social Stratification and Mobility 20: 285-323.

Edwards JR and Shipp AJ (2007) The relationship between person-environment fit and outcomes: An integrative theoretical framework. In: Ostroff C and Judge TA (eds) Perspectives on organizational fit. San Francisco: Jossey-Bass, 209-258

Federal Employment Agency (2014) Arbeitsmarkt in Zahlen, Sozialversicherungspflichtig Beschäftigte nach der ausgeübten Tätigkeit der Klassifikation der Berufe (KldB 2010). Statistik der Bundesagentur für Arbeit. Nürnberg.

Ganzeboom HBG, De Graaf PM and Treiman DJ (1992) A Standard International SocioEconomic Index of Occupational Status. Social science research 21(1): 1-56.

Gesthuizen M and Dagevos J (2008) Mismatching of persons and jobs in the Netherlands: consequences for the returns to mobility. Work, Employment and Society 22(3): 485506.

Gjerustad C (2016) Predicting unemployment: Occupational aspiration-achievement discrepancy as a risk factor in Norwegian young adults. International Journal of Social Welfare 25(4): 361-372.

Gjerustad C and Von Soest T (2011) Socioeconomic status, achieving occupational aspirations and sickness absence: A population based longitudinal study of Norwegian youths. Norsk Epidemiologi 20(1).

Gottfredson LS (1981) Circumscription and compromise: A developmental theory of occupational aspirations. Journal of counseling psychology 28(6): 545-579.

Gottfredson LS (2002) Gottfredson's theory of circumscription, compromise and selfcreation. In: D. Brown \& Associates (ed) Career choice and development. San Francisco: Jossey-Bass, 85-148

Grusky DB and Weeden KA (2006) Does the Sociological Approach to Studying Social Mobility Have a Future? In: Morgan SL, Fields G and Grusky DB (eds) Mobility and Inequality: Frontiers of Research from Sociology and Economics. Stanford: Stanford University Press, 85-108

Hardie JH (2014) The consequences of unrealized occupational goals in the transition to adulthood. Soc Sci Res 48: 196-211.

Haupt A and Ebner C (2020) Occupations and Inequality: Theoretical Perspectives and Mechanisms. KZfSS Kölner Zeitschrift für Soziologie und Sozialpsychologie 72(S1): $19-40$.

Heath C, Larrick RP and Wu G (1999) Goals as Reference Points. Cognitive Psychology 38(1): 79-109.

Higgins ET (1987) Self-discrepancy: a theory relating self and affect. Psychol Rev 94(3): 319-340. 
Holland JL (1997) Making Vocational Choices: A Theory of Vocational Personalities and Work Environments. Odessa: Psychological Assessment Resources.

Irving PG and Montes SD (2009) Met expectations: The effects of expected and delivered inducements on employee satisfaction. Journal of Occupational and Organizational Psychology 82(2): 431-451.

Jonsson JO, Grusky DB, Di Carlo M, Pollak R and Brinton MC (2009) Microclass Mobility: Social Reproduction in Four Countries. American Journal of Sociology 114(4): 977-1036.

Kalleberg AL and Mastekaasa A (2001) Satisfied Movers, Committed Stayers: The Impact of Job Mobility on Work Attitudes in Norway. Work and Occupations 28(2): 183-209.

Kanter RM (1977) Some effects of proportions on group life: Skewed sex ratios and responses to token women. American Journal of Sociology 82(5): 965-990.

Kristof-Brown AL, Zimmerman RD and Johnson EC (2005) Consequences of Individuals' Fit at Work: A Meta-Analysis of Person-Job, Person-Organization, Person-Group, and Person-Supervisor Fit. Personnel Psychology 58(2): 281-342.

McAndrew S, O'Brien D and Taylor M (2019) The values of culture? Social closure in the political identities, policy preferences, and social attitudes of cultural and creative workers. The Sociological Review 68(1): 33-54.

MacKinnon DP (2008) Introduction to statistical mediation analysis. New York: Erlbaum.

Mann A, Denis V, Schleicher A, Ekhtiari H, Forsyth T, Liu E, et al. (2018) Dream Jobs? Teenagers' Career Aspirations and the Future of Work. Paris: OECD.

Manzoni A, Härkönen J and Mayer KU (2014) Moving On? A Growth-Curve Analysis of Occupational Attainment and Career Progression Patterns in West Germany. Social Forces 92(4): 1285-1312.

Masdonati J, Lamamra N and Jordan M (2010) Vocational education and training attrition and the school-to-work transition. Education + Training 52(5): 404-414.

Matthes B, Meinken H and Neuhauser P (2015) Berufssektoren und Berufssegmente: Auf Grundlage der KldB 2010. Nürnberg: Bundesagentur für Arbeit.

Michalos AC (1985) Multiple discrepancies theory (MDT). Soc Indic Res 16(4): 347-413.

Müller W, Steinmann S and Ell R (1998) Education and labour market entry in Germany. In: Shavit Y and Müller W (eds) From School to Work: A Comparative Study of Educational Qualifications and Occupational Destinations. Oxford: Clarendon Press, 143188

Muthén LK and Muthén BO (2012-2019) Mplus Version 8.7 (statistical software). Los Angeles: Muthén \& Muthén.

Olczyk M, Will G and C. K (2014) Immigrants in the NEPS: Identifying generation status and group of origin. NEPS Working Paper No. $41 a$.

Paulus W and Matthes B (2013) The German Classification of Occupations 2010 - Structure, Coding and Conversion Table. IAB-FDZ.

Pearson CAL (1995) The Turnover Process in Organizations: An Exploration of the Role of Met-Unmet Expectations. Human Relations 48(4): 405-420.

Reay D (2005) Beyond Consciousness? The Psychic Landscape of Social Class. Sociology of Education 39(5): 911-928. 
Reynolds JR and Baird CL (2010) Is There a Downside to Shooting for the Stars? Unrealized Educational Expectations and Symptoms of Depression. American Sociological Review 75(1): 151-172.

Rochat S (2015) Encourager le rêve ou confronter à la réalité? Le dilemme des psychologues conseillers en orientation. L'Orientation scolaire et professionnelle 44(4).

Rohrbach-Schmidt D and Uhly A (2015) Determinanten vorzeitiger Lösungen von Ausbildungsverträgen und berufliche Segmentierung im dualen System. Eine Mehrebenenanalyse auf Basis der Berufsbildungsstatistik. KZfSS Kölner Zeitschrift für Soziologie und Sozialpsychologie 67(1): 105-135.

Schmid E and Stalder BE (2012) Dropping Out from Apprenticeship Training as an Opportunity for Change. In: Tynjälä P, Stenström ML and Saarnivaara M (eds) Transitions and Transformations in Learning and Education. Dordrecht: Springer, 117-130

Schwiter K, Wehner N, Maihofer A and Huber E (2011) Zur Hartnäckigkeit geschlechtssegregierender Ausbildungs- und Berufsverläufe. Konzeptionelle Überlegungen zu einer empirischen Untersuchung. femina politica 20(2): 13.

Seidel K (2019) The intention to quit apprenticeships and the role of secondary jobs. Journal of Vocational Education \& Training 71(4): 556-578.

Sennett R and Cobb J (1972) The hidden injuries of class. Cambridge: Cambridge University Press.

Siembab M and Wicht A (2020) Schulformen und geschlechtstypische Berufsorientierungen. Jugendliche am Ende der neunten Klasse zwischen Gelegenheitsstrukturen auf dem Arbeitsmarkt und schulspezifischen Berufsaspirationen. Zeitschrift für Soziologie 49(2-3): 183-199.

Solga H (2008) Lack of Training: Employment Opportunities for Low-Skilled Persons from a Sociological and Microeconomic Perspective. In: Solga H and Mayer KU (eds) Skill Formation: Interdisciplinary and Cross-National Perspectives. Cambridge: Cambridge University Press, 173-204

Stalder BE and Schmid E (2016) Lehrvertragsauflösung und Ausbildungserfolg - kein Widerspruch. Wege und Umwege zum Berufsabschluss.

Starbuck WH (1963) Level of aspiration theory and economic behavior. Behavioural Science 8(2): 128-136.

Super DE (1957) The psychology of careers; an introduction to vocational development. Oxford, England: Harper \& Bros.

Taris TW, Feij JA and Capel S (2006) Great Expectations - and What Comes of it: The Effects of Unmet Expectations on Work Motivation and Outcomes Among Newcomers. International Journal of Selection and Assessment 14(3): 256-268.

Taylor CJ (2010) Occupational Sex Composition and the Gendered Availability of Workplace Support. Gender \& Society 24(2): 189-212.

Taylor CJ (2016) "Relational by Nature"? Men and Women Do Not Differ in Physiological Response to Social Stressors Faced by Token Women. American Journal of Sociology 122(1): 49-89.

Tsaousides T and Jome L (2008) Perceived career compromise, affect and work-related satisfaction in college students. Journal of Vocational Behavior 73(2): 185-194. 
Turnley WH and Feldman DC (2000) Re-Examining the Effects of Psychological Contract Violations: Unmet Expectations and Job Dissatisfaction as Mediators. Journal of Organizational Behavior 21: 25-42.

Uhly A (2015) Vorzeitige Vertragslösungen und Ausbildungsverlauf in der dualen Berufsausbildung. Forschungsstand, Datenlage und Analysemöglichkeiten auf Basis der Berufsbildungsstatistik. Wissenschaftliche Diskussionspapiere Heft 157. Bonn: Bundesinstitut für Berufsbildung (BIBB).

Wenzelmann F and Lemmermann H (2012) Betriebliche Kosten von Vertragslösungen. Berufsbildung in Wissenschaft und Praxis (BWP) 41(5): 4-5.

Williams R (2000) A Note on Robust Variance Estimation for Cluster-Related Data. Biometrics 56: 645-646. 


\section{Appendix}

Table A1. Full regression results of the predictors of dropout from VET.

\begin{tabular}{|c|c|c|c|c|c|c|}
\hline & \multicolumn{2}{|c|}{ Field of work } & \multicolumn{2}{|l|}{ Social status } & \multicolumn{2}{|c|}{ Gender-typing } \\
\hline & $\beta$ & $S E$ & $\beta$ & $S E$ & $\beta$ & $S E$ \\
\hline \multicolumn{7}{|l|}{ Correlates with dropout } \\
\hline \multicolumn{7}{|l|}{ Main predictors } \\
\hline \multicolumn{7}{|l|}{ Field of work } \\
\hline \multicolumn{7}{|l|}{ No compromise (ref.) } \\
\hline Weak compromise & 0.009 & 0.042 & & & & \\
\hline Strong compromise & 0.154 & 0.029 & & & & \\
\hline \multicolumn{7}{|l|}{ Social status } \\
\hline \multicolumn{7}{|l|}{ No compromise (ref.) } \\
\hline Downward compromise & & & 0.063 & 0.031 & & \\
\hline Upward compromise & & & 0.086 & 0.041 & & \\
\hline \multicolumn{7}{|l|}{ Gender-type } \\
\hline \multicolumn{7}{|l|}{ No compromise (ref.) } \\
\hline Downward compromise & & & & & 0.145 & 0.034 \\
\hline Upward compromise & & & & & 0.100 & 0.030 \\
\hline
\end{tabular}




\section{Enjoyment of training}

Controls

Gender: female

Migration background

German (ref.)

$1^{\text {st }}$ generation migrant

$2^{\text {nd }}$ generation migrant

School type

Low (ref.)

Medium

High

Duration of Training

$1^{\text {st }}$ half-year (ref.)

$2^{\text {nd }}$ half-year

$2^{\text {nd }}$ year

$>2^{\text {nd }}$ year

Occupational segment

Production (ref.)

Personal service

Commercial service
$-0.153$
0.039

0.243 


\begin{tabular}{|c|c|c|c|c|c|c|}
\hline IT and scientific service & 0.016 & 0.049 & -0.012 & 0.051 & -0.001 & 0.049 \\
\hline Other economic service & -0.158 & 0.065 & -0.142 & 0.068 & -0.173 & 0.067 \\
\hline Dual training (versus school-based) & 0.044 & 0.035 & 0.042 & 0.036 & 0.039 & 0.035 \\
\hline \multicolumn{7}{|l|}{ Correlates with enjoyment } \\
\hline \multicolumn{7}{|l|}{ Main predictors } \\
\hline \multicolumn{7}{|l|}{ Field of work } \\
\hline \multicolumn{7}{|l|}{ No compromise (ref.) } \\
\hline Weak compromise & -0.068 & 0.034 & & & & \\
\hline Strong compromise & -0.144 & 0.024 & & & & \\
\hline \multicolumn{7}{|l|}{ Gender-type } \\
\hline \multicolumn{7}{|l|}{ No compromise (ref.) } \\
\hline Downward compromise & & & & & -0.068 & 0.032 \\
\hline Upward compromise & & & & & -0.071 & 0.027 \\
\hline \multicolumn{7}{|l|}{ Social status } \\
\hline \multicolumn{7}{|l|}{ No compromise (ref.) } \\
\hline Downward compromise & & & -0.070 & 0.027 & & \\
\hline Upward compromise & & & -0.056 & 0.037 & & \\
\hline \multicolumn{7}{|l|}{ Controls } \\
\hline Gender: female & 0.023 & 0.028 & 0.024 & 0.028 & 0.023 & 0.028 \\
\hline Migration background & & & & & & \\
\hline & & & & & & \\
\hline
\end{tabular}




\begin{tabular}{|c|c|c|c|c|c|c|}
\hline \multicolumn{7}{|l|}{ German (ref.) } \\
\hline $1^{\text {st }}$ generation migrant & -0.145 & 0.052 & -0.166 & 0.053 & -0.157 & 0.052 \\
\hline $2^{\text {nd }}$ generation migrant & -0.132 & 0.032 & -0.144 & 0.032 & -0.141 & 0.032 \\
\hline \multicolumn{7}{|l|}{ School type } \\
\hline \multicolumn{7}{|l|}{ Low (ref.) } \\
\hline Medium & 0.017 & 0.028 & 0.010 & 0.028 & 0.012 & 0.028 \\
\hline High & 0.012 & 0.037 & -0.010 & 0.038 & -0.013 & 0.037 \\
\hline \multicolumn{7}{|l|}{ Duration of Training } \\
\hline \multicolumn{7}{|l|}{$1^{\text {st }}$ half-year (ref.) } \\
\hline $2^{\text {nd }}$ half-year & 0.006 & 0.004 & 0.008 & 0.004 & 0.008 & 0.004 \\
\hline $2^{\text {nd }}$ year & 0.037 & 0.007 & 0.040 & 0.007 & 0.040 & 0.007 \\
\hline$>2^{\text {nd }}$ year & 0.062 & 0.011 & 0.066 & 0.011 & 0.066 & 0.011 \\
\hline \multicolumn{7}{|l|}{ Occupational segment } \\
\hline \multicolumn{7}{|l|}{ Production (ref.) } \\
\hline Personal service & -0.047 & 0.034 & -0.034 & 0.035 & -0.033 & 0.034 \\
\hline Commercial service & -0.184 & 0.032 & -0.187 & 0.033 & -0.177 & 0.032 \\
\hline IT and scientific service & -0.027 & 0.046 & 0.036 & 0.048 & -0.006 & 0.049 \\
\hline Other economic service & -0.103 & 0.056 & -0.145 & 0.050 & -0.108 & 0.056 \\
\hline Dual training (versus school-based) & 0.040 & 0.033 & 0.046 & 0.033 & 0.050 & 0.033 \\
\hline
\end{tabular}




\begin{tabular}{|c|c|c|c|c|c|c|}
\hline Dropout & 1.404 & 0.093 & 1.305 & 0.094 & 1.331 & 0.093 \\
\hline Enjoyment of training & 4.619 & 0.043 & 4.557 & 0.043 & 4.555 & 0.043 \\
\hline \multicolumn{7}{|l|}{ Residual Variance } \\
\hline Enjoyment of training & 0.481 & 0.016 & 0.484 & 0.016 & 0.484 & 0.016 \\
\hline
\end{tabular}

Note: Bootstrap and person-cluster robust S.E., 5,000 replications, N(months) 118,820, N(apprentices) 5,600. 
Table A2. Correlation matrix of study variables.

\begin{tabular}{|c|c|c|c|c|c|c|c|c|c|c|c|c|c|c|c|c|}
\hline Variables & (1) & (2) & (3) & (4) & (5) & (6) & (7) & $(8)$ & (9) & $(10)$ & $(11)$ & (12) & (13) & (14) & $(15)$ & $(16)$ \\
\hline (1) dropout & 1.000 & & & & & & & & & & & & & & & \\
\hline (2) comp.: field of work & 0.060 & 1.000 & & & & & & & & & & & & & & \\
\hline (3) comp.: gender type & 0.040 & 0.767 & 1.000 & & & & & & & & & & & & & \\
\hline (4) comp.: social status & 0.032 & 0.696 & 0.518 & 1.000 & & & & & & & & & & & & \\
\hline (5) enjoyment & -0.190 & -0.161 & -0.103 & -0.084 & 1.000 & & & & & & & & & & & \\
\hline (6) gender & 0.040 & 0.065 & 0.196 & 0.191 & -0.051 & 1.000 & & & & & & & & & & \\
\hline (7) native & -0.161 & -0.128 & -0.097 & -0.078 & 0.170 & -0.081 & 1.000 & & & & & & & & & \\
\hline (8) $1^{\text {st }}$ gen. migrant & 0.138 & 0.127 & 0.128 & 0.013 & -0.110 & 0.010 & . & 1.000 & & & & & & & & \\
\hline (9) $2^{\text {nd }}$ gen. migrant & 0.127 & 0.099 & 0.059 & 0.088 & -0.155 & 0.093 & . & -0.940 & 1.000 & & & & & & & \\
\hline (10) school type & -0.246 & 0.254 & 0.220 & 0.292 & -0.030 & 0.186 & 0.186 & -0.194 & -0.140 & 1.000 & & & & & & \\
\hline (11) production & -0.079 & -0.091 & -0.251 & -0.286 & 0.147 & -0.796 & 0.106 & -0.044 & -0.109 & -0.237 & 1.000 & & & & & \\
\hline (12) personal service & 0.137 & -0.059 & 0.101 & 0.184 & 0.011 & 0.716 & -0.062 & -0.024 & 0.083 & -0.006 & . & 1.000 & & & & \\
\hline (13) commercial service & -0.040 & 0.150 & 0.135 & 0.061 & -0.175 & 0.398 & -0.090 & 0.083 & 0.071 & 0.291 & & -0.986 & 1.000 & & & \\
\hline (14) IT/scientific service & -0.044 & 0.004 & 0.026 & 0.265 & 0.022 & -0.336 & 0.118 & -0.078 & -0.110 & 0.246 & -0.974 & -0.959 & . & 1.000 & & \\
\hline (15) other economic service & -0.042 & 0.119 & 0.176 & -0.035 & -0.060 & -0.374 & -0.007 & 0.046 & -0.012 & -0.244 & . & & . & . & 1.000 & \\
\hline (16) dual training & -0.214 & -0.078 & -0.107 & -0.280 & 0.030 & -0.462 & 0.024 & 0.015 & -0.035 & -0.077 & 0.486 & -0.688 & 0.378 & -0.124 & 0.381 & 1.000 \\
\hline
\end{tabular}

Note: displayed are Pearson moment correlations (continuous variables), polychoric correlations (nominal/ordinal variables) and polyserial correlations (nominal/ordinal and continuous variables). N(months) 118,820 ,

N(apprentices) 5,600 . 